\title{
Morphometric Analysis of the Corpus, Spinal Canal and Torg Ratio Using Midsagittal Cervical Vertebrae Computed Tomography Scan: Indonesian Population
}

\author{
Rully Hanafi Dahlan, ${ }^{1}$ Farid Yudoyono, ${ }^{1}$ Priandana Adya Eka Saputra, ${ }^{2}$ Sevline Esthetia Ompusunggu, \\ Muhammad Zafrullah Arifin, ${ }^{2}$ Agung Budi Sutiono, ${ }^{2}$ Ahmad Faried ${ }^{2}$ \\ ${ }^{1}$ Spine Research Laboratory, Department of Neurosurgery, Faculty of Medicine, Universitas Padjdajaran- \\ Dr. Hasan Sadikin General Hospital \\ ${ }^{2}$ Department of Neurosurgery, Faculty of Medicine, Universitas Padjajaran-Dr. Hasan Sadikin General \\ Hospital
}

\begin{abstract}
Objective: To determine the normal ranges of cervical spinal canal morphometry in Indonesian population and to compare the acquired data collected from other populations

Methods: Computed tomography measurements on the diameter of midsagital spinal canal and corpus of cervical vertebrae and its Torg ratio from the lower cervical (C3-C7) canal from 24 normal Indonesian adults were performed at the Radiology Department of Dr. Hasan Sadikin General Hospital. Patients who had cervical spine disorders and those under 20 years old were exluded. We used computed tomography scan midsagittal view to measure the aforementioned parameters.
\end{abstract}

Results: The average diameter for the cervical spinal canals for the Indonesian population is comparable with those of other Asian populations such as Hongkong and India, albeit with smaller Torg ratio.

Conclusions: This study reports the normal radiological anatomy of the midsagital spinal canal and corpus of cervical vertebrae as well as Torg ratio from the lower

Received:

February 3, 2014

Revised:

April 14, 2014

Accepted:

June 24, 2014 cervical vertebrae among Indonesian population. The measurements result of this study shows that, although slightly smaller, the measurement results for those parameters are identical with other Asian populations.

Keywords: Corpus cervical vertebrae, midsagittal cervical spinal canal, Torg ratio

IJIHS. 2014;2(1):36-9

\section{Introduction}

One of the predisposing factors for neck problems is cervical spinal canal stenosis, a condition in which the diameter of the cervical spinal canal is less than the normal measurement for the relevant age or sex of the individuals. ${ }^{1-5}$ So far, there are several radiological and morphological anatomic studies on the size of spinal canal in different populations in the world. ${ }^{1-6}$

Plain lateral $\mathrm{x}$-ray is usually used to determine the canal diameter. However, there are many

\footnotetext{
Correspondence:

Farid Yudoyono, Spine Research Laboratory, Department of Neurosurgery, Faculty of Medicine, Universitas Padjadjaran-Dr. Hasan Sadikin General Hospital Jl. Pasteur No. 38, Bandung, Indonesia e-mail: faridspine@gmail.com
}

limitations found in terms of value intepretation when using this method. ${ }^{1,3,7,8}$ We used computed tomography (CT) scan imaging to measure the parameters being studied, i.e. midsagital spinal canal and corpus of cervical vertebrae diameters and the Torg ratio from lower cervical (C3-C7) canal. The method of analyis used was Torg and Pavlov canal-to-corpus ratio, in which the magnification factor could be omitted.,2,3 Cervical CT scan was used because it gives better image of the bone; thus, allows us to gain more accurate measurements compared to manual measurement. ${ }^{9,10}$

To our knowledge, until recently, there have been no report or study mentioning the cervical spinal canal morphometry for Indonesian population. Therefore, this study aimed to 

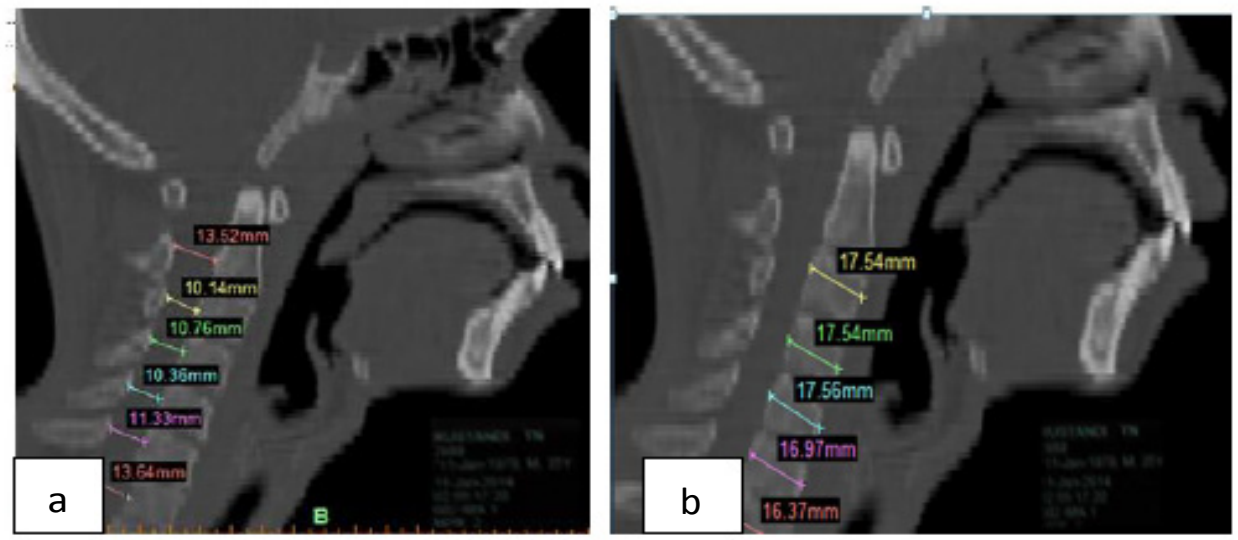

Fig. 1 Spinal Canal Computed Tomography Scan (Fig. 1a) Measurement of Midsagittal Cervical Corpus (Fig. 1b)

determine the normal ranges of cervical spinal canal morphometry in Indonesian population and to compare the acquired data from other populations.

\section{Methods}

Computed tomography measurements of the midsagital spinal canal and corpus of cervical vertebrae diameters and the Torg ratio from lower cervical (C3-C7) canal were performed on 24 normal Indonesian adults at the Department of Radiology, Dr. Hasan Sadikin General Hospital. Patients with cervical spine disorders and those under 20 years old were excluded. We used CT scan of midsagittal cervical to measure aforementioned parameters.

\section{Results}

The means of the cervical spinal canal diameter are presented below (Table 1). In terms of Torg ratio criteria, the Hongkong population has the smallest value in all spinal level and India has the biggest value in all spinal level. Although slightly smaller, the measurement results for those parameters in this study are identical with those from other Asian population (Table 2).

\section{Discussion}

The cervical spines consist of eight vertebras. The third until eight cervical vertebras are "common" cervical vertebra, while C1 (atlas) and C2 (axis) are the atypical ones. The cervical spinal canal is an opening within cervical vertebras in which the cervical spinal cord runs. Its boundaries are vertebral bodies, bilateral pedicles and laminae, and spinous processes. The canal follows the normal contour of spine. The shape of the cervical spinal canal is triangular, which is the same as the lumbar region. The diameter of the cervical spinal canal is fairly large in the upper cervical region but narrows down from C3 and inferiorly, where the diameter is approximately $12-13 \mathrm{~mm}$ in the

Table 1 Cervical Vertebrae Spinal Canal Diameters, Vertebral Body Diameters and Torg Ratio in Indonesian population

\begin{tabular}{|c|c|c|c|c|c|}
\hline \multirow{2}{*}{ Parameter } & C3 (n=25) & C4 (n=25) & C5 $(n=25)$ & C6 $(n=25)$ & $C 7(n=25)$ \\
\hline & Mean \pm SD & Mean士SD & Mean士SD & Mean士SD & Mean $\pm S D$ \\
\hline Spinal canal diameter (mm) & $11.24 \pm 1.15$ & $11.32 \pm 1.27$ & $1153 \pm 1.21$ & $11.97 \pm 1.55$ & $12.32 \pm 1.36$ \\
\hline Vertebral body diameter (mm) & $14.37 \pm 2.20$ & $14.90 \pm 2.03$ & $15.09 \pm 1.78$ & $15.60 \pm 1.83$ & $15.41 \pm 1.35$ \\
\hline Torg ratio & $0.81 \pm 1.9$ & $0.78 \pm 0.18$ & $0.78 \pm 0.15$ & $0.78 \pm 0.15$ & $0.81 \pm 1.15$ \\
\hline
\end{tabular}




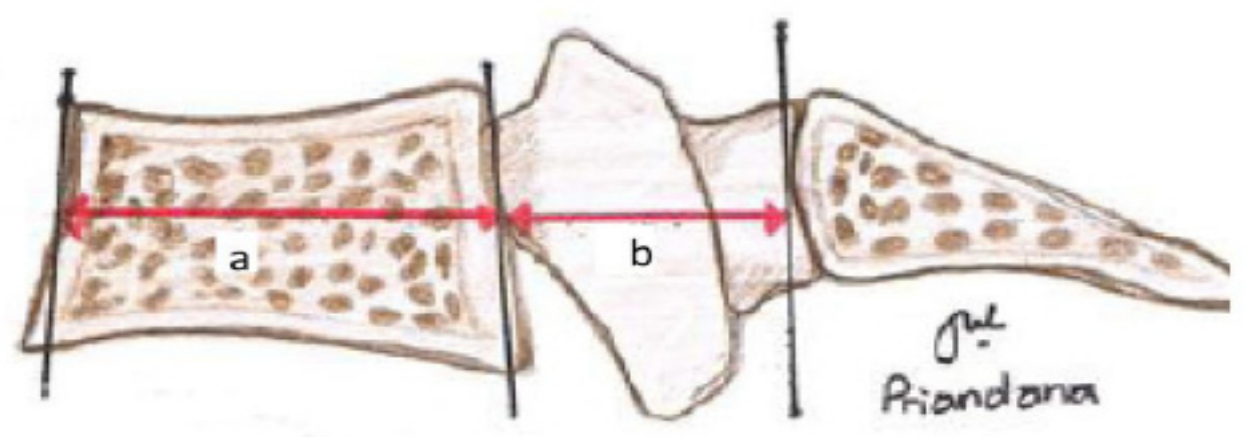

Fig. 2 llustration of Torg Ratio = b/a, (a) Anterior Posterior Corpus Length, (b) Spinal Canal
Length

anteroposterior plane. The space in the spinal canal allows for the free movement of the canal contents without tension or pressure during these movements. Therefore, the normal size of the canal is important. An abnormal reduction in the size of the spinal canal could predispose the individual to neck pain. Due to the narrowing, the lower cervical cord is particularly vulnerable to a variety of pathological entities, one of which is canal stenosis, that could compromise the cord within the vertebral canal. The stenosis of the cervical spinal canal is an anatomical anomaly which is more common than realized. Individuals with this anomaly tend to remain neurologically asymptomatic until a complicating feature, such as osteophytes or herniated intervertebral discs, develops.
Several studies have been performed to prove that measurement of the sagittal diameter of the cervical canal in plain lateral radiography is a useful method for detecting cervical spinal stenosis. ${ }^{2,4,7,11}$ However, comparison of published data reveals that the range of variation in the reported sagittal diameter is considerable. ${ }^{1,3-6,10}$ Those diversity is partly due to the variation in the radiographic technique (focus-to-film distance) and variation in the body build of the subjects (affecting the object-to-film distance). In an attempt to find a solution to these discrepancies, Torg et al. ${ }^{12}$ devised a measurement ratio that compares the sagittal diameter of the spinal canal with the anteroposterior width of the vertebral body, in which both of those are equally affected by radiological magnification factors. ${ }^{2,6,9}$

Table 2 Torg Ratio on Lateral Radiographs of Cervical Spine

\begin{tabular}{llcccccc}
\hline \multirow{2}{*}{ Country } & \multirow{2}{*}{ Author's (Year) } & \multirow{2}{*}{$\begin{array}{l}\text { Sample's } \\
\text { Number }\end{array}$} & \multicolumn{6}{c}{ C3 } & C4 & C5 & C6 & C7 \\
\cline { 5 - 8 } Indonesia & $\begin{array}{l}\text { Arifin et al. } \\
\text { (2013) }\end{array}$ & 25 & $0.81 \pm 1.9$ & $0.78 \pm 0.18$ & $0.78 \pm 0.15$ & $0.78 \pm 0.15$ & $0.81 \pm 1.15$ \\
\cline { 5 - 8 } India & $\begin{array}{l}\text { Kathole et al. } \\
(2012)\end{array}$ & 300 & $1.005 \pm 0.06$ & $1.01 \pm 0.07$ & $1.015 \pm 0.07$ & $1.02 \pm 0.07$ & $1.015 \pm 0.07$ \\
Korea & $\begin{array}{l}\text { Song et al. } \\
\text { (2009) }\end{array}$ & 53 & $0.84 \pm 0.13$ & $0.83 \pm 0.13$ & $0.85 \pm 0.14$ & $0.85 \pm 0.13$ & $0.85 \pm 0.12$ \\
Turkey & $\begin{array}{l}\text { Karabulut and } \\
\text { Karabulut (2007) }\end{array}$ & 90 & $0.86 \pm 0.14$ & $0.76 \pm 0.17$ & $0.83 \pm 0.16$ & $0.825 \pm 0.14$ & $0.81 \pm 0.13$ \\
Hongkong & $\begin{array}{l}\text { Wong et al. } \\
(2004)\end{array}$ & 36 & $0.77 \pm 0.17$ & $0.75 \pm 0.17$ & $0.76 \pm 0.17$ & $0.76 \pm 0.17$ & $0.78 \pm 0.21$ \\
\hline
\end{tabular}


This ratio is obtained by dividing the midsagittal diameter of the cervical spinal canal at any particular cervical segment by the midsagittal diameter of the corresponding vertebral body. It has been reported that, using the ratio method as standard, a measurement of less than 0.80 indicates significant spinal stenosis.

Usefulness of Torg's ratio in the diagnosis of cervical spinal canal stenosis has also been confirmed by several other studies. ${ }^{1,7,10}$ Studies have also been performed in order to determine the mean anteroposterior diameter of the cervical spinal canal at different vertebral levels in normal subjects making it possible, clinicians

\section{References}

1. Maqbool A, Athar Z, Hussain L. Midsagittal diameter of cervical spinal canal and Torg's ratio of the cervical spine in Pakistanis. Pakistan J Med Sci. 2003;19(3):203-10.

2. Wong $\mathrm{TM}$, Leung $\mathrm{HB}$, Wong WC. Correlation between magnetic resonance imaging and radiographic measurement of cervical spine in cervical myelopathy patients. J Orthop Surg. 2004;12 (2):239-42.

3. Song KJ, Choi BW, Kim SJ, Kim GH, Kim YS, Song $\mathrm{JH}$. The relationship between spinal stenosis and neurological outcome in traumatic cervical spine injury: an analysis using Pavlov ratio, spinal cord area and spinal canal area. Clin Orthop Surg. 2009;1(1):11-8.

4. Tossel G. Dimension of the cervical spinal canal in the South African Negroid population. [dissertation]. South Africa: School of Medicine, Faculty of Health Science, University of Pretoria; 2005.

5. Tjahjadi D, Onibala MZ. Torg ratios based on cervical lateral plain films innormal subjects. Universa Medicina. 2010;29(1):8-13.

6. Kathule MA, Joshi RA, Herekar NG, Jadhav SS. Dimensions of cervical spinal canal and their relevance in clinical practice. Int J Recent Trends to diagnose cervical spinal stenosis by consulting these reference values. ${ }^{1-4,7}$ Comparing those studies with ours, it is revealed that our measurement data is similar with those of other studies.

In conclusion, this study reports the normal radiological anatomy of the midsagital spinal canal and corpus of cervical vertebrae and the Torg ratio from the lower cervical vertebrae among adult Indonesian. The measurements results of this study show that, although the Torg ratio is slightly smaller, they are similar and comparable with those from other Asian populations.

\section{Sci Tech. 2012;3(2):54-8.}

7. Karabulut Ö, Karabulut Z. The variations of Torg Ratio with gender in patients with neck pain. Dicle Med J. 2007;34(4):272-4.

8. Choudhary S, Kattimuthu P, Kataria SK. A radiographic study of sagittal diameter of cervical spinal canal in adult male population of Rajasthan. Asian J Med Res. 2013;2(1):7-9.

9. Gour KK, Shrivastava SK, Thakare AE. Size of cervical vertebral canal-measurements in lateral cervical radiographs \& dried bones. Int J Biol Med Res. 2011;2(3):778-80.

10. Suk KS, Kim KT, Lee JH, Lee SH, Kim JS, Kim JY. Reevaluation of the Pavlov ratio in patients with cervical myelopathy. Clin Orthop Surg. 2009;1(1):6-10.

11. Kang SK, Park JY, Chin DK, Kim KH, Kuh SU, Kim $\mathrm{KS}$, et al. A PET/CT-based study of spinal canal in Korean young adults: anteroposterior diameter from cervical vertebra to sacrum. Korean J Spine. 2012;9(3):165-9.

12. Torg JS, Corcoran TA, Thibault LE, Pavlov H, Sennett BJ, Naranja RJ Jr, et al. Cervical cord neurapraxia: classification, pathomechanics, morbidity, and management guidelines. J Neurosurg. 1997;87(6):843-50. 